\title{
NON-SURGICAL MANAGEMENT OF A CASE OF AMLODIPINE-INDUCED GINGIVAL ENLARGEMENT
}

\author{
Maj Raghavendra M. H ${ }^{1}$ Col A. K. Shreehari², Maj Devendra Srivastava ${ }^{3}$
}

\section{HOW TO CITE THIS ARTICLE:}

Raghavendra M. H, A. K. Shreehari, Devendra Srivastava. "Non-Surgical Management of a Case of AmlodipineInduced Gingival Enlargement". Journal of Evolution of Medical and Dental Sciences 2014; Vol. 3, Issue 37, August 21; Page: 9685-9689, DOI: 10.14260/jemds/2014/3252

ABSTRACT: Gingival enlargement (GE) is a frequent finding in many gingival and periodontal diseases with or without associated systemic conditions. It is an undesirable side effect seen in patients on medication for many non-dental conditions. Calcium channel blocker (CCBs), immunosuppressants and anticonvulsants are the commonly involved drugs for GE. Among CCBs, a higher incidence has been reported in literature with the use of nifedipine (upto 10\%) and much lower incidence with others like Amlodipine. However, increasingly large number of patients with Amlodipine associated gingival enlargement (AAGE) has been reported in recent times. This case reports highlights the treatment protocol followed in the management a case of AAGE and thereby sensitizing the clinicians in this regard.

KEYWORDS: Non-Surgical Periodontal Therapy, Amlodipine, Chronic Periodontitis.

INTRODUCTION: Drug-induced gingival enlargement was first reported in 1939 by Kimball with chronic usage of the antiepileptic drug phenytoin. ${ }^{1}$ Currently, more than 20 prescription medications are associated with gingival enlargement. ${ }^{2}$ Drugs associated with gingival overgrowth can be broadly categorized into three major groups according to their therapeutic actions, namely, anticonvulsants, immunosuppressants, and calcium channel blockers. ${ }^{3,4}$

Amlodipine is a dihydropyridine calcium channel blocker that is used in the management of both hypertension and angina. Ellis et al ${ }^{5}$ first reported gingival sequestration of amlodipine and amlodipine-induced gingival overgrowth. Since then, very few cases of amlodipine-induced gingival hyperplasia have been reported in the dental literature although there are numerous reports of nifedipine (another member of calcium channel blockers) induced gingival overgrowth. There are even less data on reports of hyperplasia with amlodipine at lower doses.6,7

In the present case, the gingival hyperplasia occurred at a dose of $5 \mathrm{mg}$ within 6 months of use. The treatment was included non-surgical periodontal therapy (scaling and root planning) and also drug substitute.

CASE REPORT: A 32-year-old male patient came to the department with the chief complaint of loose teeth in upper and lower front jaw regions since 6 months with swollen and bleeding gums. Patient first noted bead like nodular growth over the gums which progressively enlarged to the present size covering almost entire teeth interfering with further cleaning of teeth.

The patient was hypertensive since 1 year and was under medication atenolol $50 \mathrm{mg}$ and amlodipine $5 \mathrm{mg}$ once daily. No history of any adverse habits. The patient was moderately built and nourished with no signs of anemia and jaundice and non-cyanosed. His vital signs were within the normal range. 
Intraoral examination revealed generalized enlargement of attached gingiva extending up to marginal and interdental gingiva. Surface of the gingiva appeared lobulated with loss of scalloping (Figure 1). Patient oral hygiene was poor and local irritating factors were surrounded the teeth.

Based on drug history and clinical examination of the patient, a provisional diagnosis of combined gingival enlargement was made. Complete hemogram of the patient was done, but all the parameters were within the normal limits. Orthopantomogram revealed horizontal pattern with severe generalized type of bone loss (Figure 2).

An incisional biopsy revealed few areas of hyperplastic, orthokeratinized and parakeratinised stratified squamous epithelium and connective tissue exhibiting mixture of dense and loose fibrous component. Inflammatory cell infiltrate with Polymorpholeukocytes (PMLs) and dilated blood capillaries were also evident.

Correlating history, clinical examination and investigations, final diagnosis of combined gingival enlargement (amlodipine induced and inflammatory) was made. In the preliminary phase, drug substitution carried out after consulting his physician followed by scaling and root planning. Patient was on tablet Labetalol $100 \mathrm{mg}$ twice daily and was evaluated after the period of 3 months. There was a drastic change in the clinical picture of gingiva with complete loss of inflammatory component (Figure 3, 4).

DISCUSSION: Amlodipine is a 3rd generation dihydropyridine calcium antagonist which is structurally similar to nifedipine. In hypertensive patients, literature reports the prevalence of AAGE is lower than that associated with other calcium channel blocking agents including nifedipine. ${ }^{6}$ AAGE usually occurs within the first 3 months of initiation of drug therapy at a dose of $10 \mathrm{mg} / \mathrm{day}$ and begins as an enlargement of the interdental papilla. Although few cases of AAGE have been reported, the present case is interesting as it occurred with a low dose of amlodipine $(5 \mathrm{mg})$ and appeared on administration for 6 months.

Seymour et $a^{8}$ gave a review on the pathogenesis of drug-induced gingival overgrowth in which they considered it as a multifactorial model, involving an interaction of several factors, which expands on the interaction between drug and metabolite with the gingival fibroblasts.

The underlying mechanism behind drug-induced gingival hyperplasia involves inflammatory and non-inflammatory pathways. The proposed non-inflammatory mechanisms include defective collagenase activity due to decreased uptake of folic acid, blockage of aldosterone synthesis in adrenal cortex, and consequent feedback increase in adrenocorticotropic hormone level and upregulation of keratinocyte growth factor. Alternatively, inflammation may develop as a result of direct toxic effects of concentrated drug in gingival crevicular fluid and/or bacterial plagues. This inflammation could lead to the up regulation of several cytokine factors such as transforming growth factor- $\beta 1.9,10,11$

Many studies have been conducted which shows that amlodipine cannot induce gingival hyperplasia at $5 \mathrm{mg}$ once daily dose even if taken for more than 6 months. It can be caused only at a dose of $10 \mathrm{mg} /$ day.7,8 The present case is unique in that even $5 \mathrm{mg} /$ day dose of amlodipine caused gingival hyperplasia after 6 months of use.

The mechanism through which these drugs induce gingival enlargement is still poorly understood. It has been found that phenytoin and calcium channel blockers inhibit the intracellular $\mathrm{Ca} 2+$ uptake thereby stimulating gingival fibroblasts. Not all the patients receiving the same drug 
develop gingival enlargement. Possible reason can be that individuals with gingival enlargement have fibroblasts with an abnormal susceptibility to the drug.

It has also been proposed that the susceptibility to pharmacologically induced gingival enlargement may be governed by existence of differential proportions of fibroblast subset in each individual which exhibit a fibrogenic response to these medications. It has also been shown that the functional heterogenicity exists in gingival fibroblasts in response to various stimuli. ${ }^{2}$

Treatment consists of stopping the offending drug if possible with the patient's physician consent and providing the supplements of folic acid and ascorbic acid. Reduction in the size of the gingival overgrowth has been reported within a week of drug withdrawal and may lead to full resolution. ${ }^{13,14}$

Patients benefit from effective oral hygiene measures, professional tooth cleaning, scaling, and root planning. ${ }^{15}$ If gingival enlargement persists after careful consideration of the previously mentioned approaches, these cases need to be treated by surgery, either by gingivectomy or flap surgery.

In present case patient was subjected to planned sessions of scaling and root planning with substitute drug Labetalol $100 \mathrm{mg}$ twice daily. Patient follows up after 3 months revealed improvement in clinical picture of gingiva with complete loss of inflammatory component was seen. One year follow up revealed a clinically healthy gingiva indicative of a successful treatment outcome.

\section{CONCLUSION:}

1. Gingival hyperplasia may occur with amlodipine at a dose as low as $5 \mathrm{mg}$.

2. Clinician should be aware of the medications that can induce gingival hyperplasia and associated changes in the oral cavity so as to prevent, diagnose, and successfully manage such patients.

3. The treatment includes surgical or non-surgical periodontal therapy along with drug substitute.

4. The present case was successfully managed by drug substitution followed by non-surgical periodontal therapy.

\section{REFERENCES:}

1. Pradhan S, Mishra P. Gingival enlargement in antihypertensive medication. Journal of the Nepal Medical Association 2009; 48: 149-52.

2. Rees T D, Levine R. Systemic drugs as a risk factor periodontal disease initiation and progression. Compendium of Continuing Education in Dentistry 1995; 16: 20-42.

3. Informational Paper. Drug associated gingival enlargement. Journal of Periodontology 2004; 75: 1424-31.

4. Garzino-Demo P, Carbone M, Carrozzo M, Broccoletti R, Gandolfo S. An increase in gingival volume induced by drugs (phenytoin, cyclosporine and calcium antagonists) - A review of the literature. Minerva Stomatologica 1998; 47: 387-98.

5. Ellis JS, Seymour RA, Steele JG, Robertson P, Butler TG, Thomason JG. Prevalence of gingival overgrowth induced by calcium channel blockers: a community-based study. Journal of Periodontology 1999; 70: 63-7.

6. Jorgensen MG. Prevalence of amlodipine-related gingival hyperplasia. Journal of Periodontology 1997; 68: 676-8. 
7. Triveni MG, Rudrakshi C, Mehta DS. Amlodipine-induced gingival overgrowth. Journal of Indian Society of Periodontology 2009; 13: 160-3

8. Seymour RA, Thomason JA, Ellis JS. The pathogenesis of drug-induced gingival overgrowth. Journal of Clinical Periodontology. 1996; 23: 165-75

9. Nyska, Shemesh M, Tal H, Dayan D. Gingival hyperplasia induced by calcium channel blockers: mode of action. Medical Hypotheses 1994; 43: 115-8.

10. Marshall RI, Bartold PM. A clinical review of drug-induced gingival overgrowths. Australian Dental Journal 1999; 44: 219-32.

11. Lafzi, Farahani RMZ, Shoja M. Amlodipine-induced gingival hyperplasia. Medicina Oral, Patología Oral y Cirugía Bucal 2006; 11:480-2.

12. Seymour RA. Calcium channel blockers and gingival overgrowth. British Dental Journal 1991; 170: 376-9.

13. Sonmez S, Cavdar C, Gunduz C et al. Do MMP-1 levels of gingival fibroblasts have a role in the gingival overgrowth of cyclosporine-treated patients? Transplantation Proceedings 2008; 40:181-3.

14. Raman PG, Mishra VN, Singh D. Nifedipine induced gingival hyperplasia. The Journal of the Association of Physicians of India 1988; 36: 231-3.

15. Mavrogiannis M, Ellis JS, Thomason JM, Seymour RA. The management of drug-induced gingival overgrowth. Journal of Clinical Periodontology 2006; 33: 434-9.

Fig. 1: Showing generalized amlodipine -induced gingival enlargement enlargement.

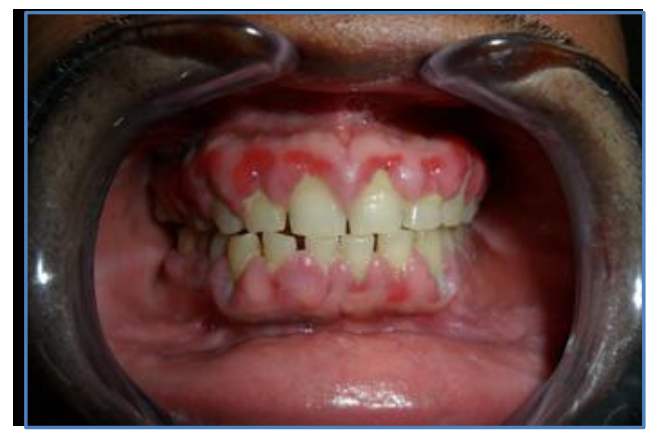

Fig. 1

Fig. 2: Orthopantomograph revealed generalized bone loss.

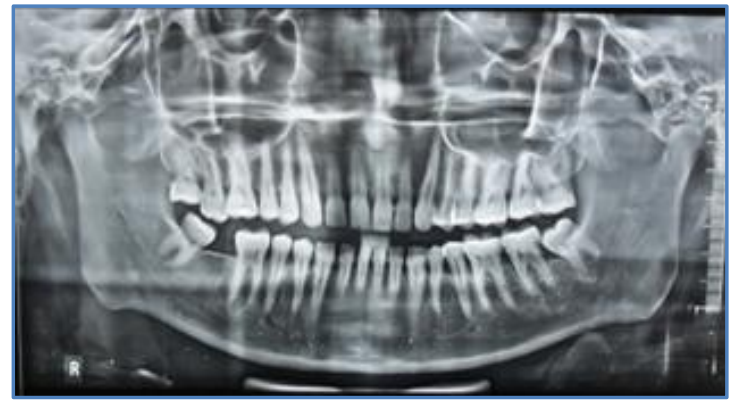

Fig. 2 


\section{CASE REPORT}

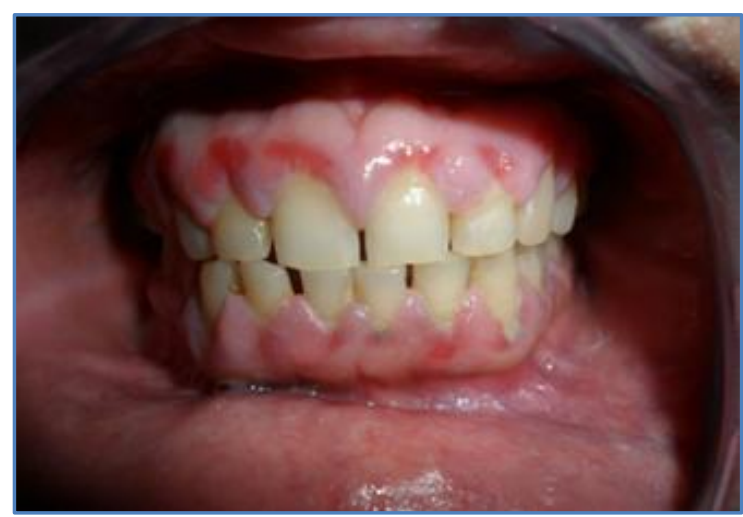

Fig. 3: Showing response to therapy after 1 months

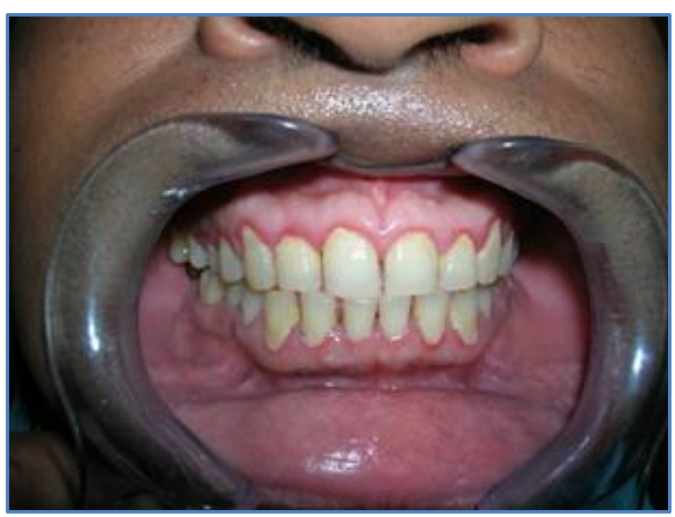

Fig. 4: Showing response to therapy after 6 months

\section{AUTHORS:}

1. Maj. Raghavendra M. H.

2. Col A. K. Shreehari

3. Maj Devendra Srivastava

\section{PARTICULARS OF CONTRIBUTORS:}

1. Resident, Department of Dental Surgery (Division of Periodontology), AFMC, Pune.

2. Associate Professor, Department of Dental Surgery, AFMC, Pune.

3. Resident, Department of Dental Surgery (Division of Periodontology), AFMC, Pune.

\section{NAME ADDRESS EMAIL ID OF THE} CORRESPONDING AUTHOR:

Maj. Raghavendra M. H,

Resident,

Department of Dental Surgery,

(Division of Periodontology),

Armed Forces Medical College,

Pune-411040.

Email: raghavendramh87@gmail.com

Date of Submission: 09/06/2014.

Date of Peer Review: 10/06/2014.

Date of Acceptance: $12 / 08 / 2014$.

Date of Publishing: 21/08/2014. 